\title{
Abyphipr - Perspective Insecticide on the Basis of Fipronil and Abomectin for Combating Zoophilnium Flies - Intermediate Bells of Belts
}

\author{
Larisa Aleksandrovna Glazunova \\ candidate of veterinary sciences, associate \\ professor, \\ ASRIVEA - Branch of Tyumen Scientific Centre SB RAS \\ Tyumen, Institutskay 2, Russia, \\ E-mail: glazunovala@gausz.ru
}

\author{
Yuri Valerievich Glazunov \\ candidate of biological sciences, associate professor, \\ FSBEI HE Northern Trans-Ural SAU \\ Tyumen, Respubliky 7, Russia, \\ E-mail: glazunovurii@mail.ru
}

\begin{abstract}
Cattle thelaziasis is widespread on many continents. The disease is characterized by damage to the organs of vision, the development of conjunctivitis, keratitis and corneal ulcers, the development of panophthalmia is often observed, and therefore, animals are culled. Since the vector of invasion is zoophilic flies, it is rational to carry out insecticidal treatments for the prevention of vegetation during the pasture period.

To protect animals from zoophilic flies, we studied the insecticidal activity of the drug "Abifipr", which consists of fipronil and abamectin, which allows to deal with resistant populations of flies. Studies were conducted in 2012-2014. in the farms of the Tyumen region, located in the forest-steppe climatic zone. When selecting an effective dosage, "Abifipr» was tested in doses of $1.0 ; 2.5 ; 5.0 ; 7.5$ and $10.0 \mathrm{ml}$ by local application to or behind elevations between the horns. Counting for the number of zoophilic flies around the eyes was carried out during 3 minutes before treatment and after $4,12,24,36,48,60,72,84,96,108$ and 120 hours after treatment, after which the coefficient of protective action was calculated.

Our research has shown that a local application of «Abifipr» in a dose of $5.0 \mathrm{ml}$ with an interval of 7-10 days in a low population of zoophilic flies and once every five days in periods of high abundance of zoophilic flies, has a high protective effect against zoophilic flies - intermediate hosts of Thelazia. The cost of insecticidal treatments per animal for the entire period of parasitizm of zoophilic flies amounted to $\mathbf{7 9 4 . 9 2}$ rubles.
\end{abstract}

Key words - zoophilic flies; cattle, thelaziasis, insecticides, fipronil, abamectin.

\section{INTRODUCTION}

Cattle thelaziasis is widespread on many continents of the globe $[1,6]$. The disease is common among many species of animals, but cattle are the most affected. It is worth remembering about the likelihood of a human becoming infected with thelaziasis, such cases are fixed in different parts of Europe, Asia and North America, and the causative agents of this invasion in humans are not only Thelazia callipaeda (parasite of dogs), but also Thelazia gulosa, which is the main causative agent of thelaziasis in the Northern Trans-Urals [2, 10, 11, 17-19]. Animal diseases cause significant economic damage to the agro-industrial complex of the country. Thelazias have mechanical, allergic and toxic effect on the host organism. Zoophilic flies, being vectors of Thelazias, also have an inoculatory effect, which contributes to the complication of the underlying disease with conjunctivitis, keratitis, clouding and ulceration of the cornea, which in turn leads to vision loss and culling of animals (Figure 1). Infected animals lose their milk production to $20-45 \%$, while the fat content of milk also decreases to $0.1 \%$. Infected young calves reduce their meat productivity, for the period of the disease the losses amount to $10-28 \mathrm{~kg}$. In addition, the cost of therapeutic and prophylactic measures is required. [3].

Sick animals, being on a pasture, become a source of invasion and flies, feeding on the eye area, swallow the larvae of Thelazias, after which metamorphosis of helminths takes place in their bodies. Upon repeated contact with animals, Thelazias leave the bodies of zoophilic flies and invade new animals. Considering the pathogen's biology, it is advisable to carry out preventive measures aimed at: 1 . killing parasites in animals' organisms and 2. destroying the intermediate hosts of Thelazias - zoophilic flies. The features of the parasite's biology dictate the necessity of carrying out these actions in different periods of the year $[5,12,15,16]$

For the destruction of parasites in animals' bodies, it is rational to carry out the de-worming of the entire livestock before sending out on pasture, or after taking it to stables. For this purpose, it is advisable to use anti-helminth drugs of systemic action.

The fight against intermediate hosts of Thelazias must be carried out by the constant use of prevention and extermination measures. Their performance in regulating the number of each group of zoophilic flies is not the same. Thus, preventive measures are most effective in the fight against flies indoors, and destructive measures are more effective when used on pastures $[4,14,15]$.

On large livestock farms and complexes, preventive measures include a set of sanitary and economic measures aimed at eliminating places of feeding and developing of flies indoors and preventing their flight into the premises. Insecticides continue to remain the main means of fighting 
zoophilic flies. The search for new environmentally friendly methods for insecticides use is one of the greatest challenges in agriculture at the present stage.

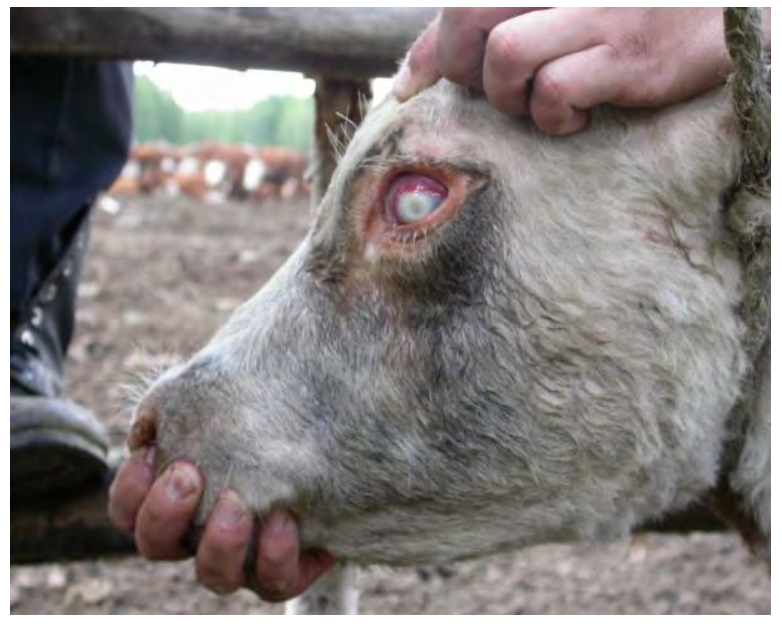

Fig. 1. Clinic signs of thelaziasis

Previously animals were protected from pastures flies by spraying insecticides from the group of carbamate and organophosphorus compounds, as well as bacterial-based drugs to which the flies are capable of evolving resistance.

Currently, scientists and practitioners focus on the testing and implementation of synthetic pyrethroids [4, 7]. However, it is known that flies develop resistance after multi-year use of synthetic pyrethroids, which forces the scientists to seek new means $[8,9]$.

Taking into account all the above, we set a goal to examine the effectiveness of chemical insecticides based on fipronil and abamectin for the prevention of cattle thelaziasis [15].

\section{MATERIALS AND METHODS}

This research was conducted in the period from 2012 to 2014 on the basis of acarology laboratory of the All-Russian Scientific Research Institute of Veterinary Entomology and Arachnology - a branch of the Federal State Budgetary Institution of Science of the Federal Research Center of the Tyumen Scientific Center of the Siberian Branch of the Russian Academy of Sciences - and the Department of Infectious and Invasive Diseases of the Federal State Budgetary Educational Institution of the State Agrarian University of Northern TransUrals in accordance with a research plan. As a prototype of the drug, «Abifipr» was tested - an insecticoacaricidal preparation containing fipronil and abamectin, used by the pur-on method, developed at the VNIIVEA branch (All-Russian Scientific Research Institute of Veterinary Entomology and Arachnology) of Tyumen Research Center of the Siberian Branch of the Russian Academy of Sciences.

The experimental part of insecticide dose selection was carried out in June 2012 in LLC «Zubr» of the Golyshmanovskiy district on adult beef cattle in the period of the maximum number of zoophilic flies. For this purpose, 5 experimental and 1 control group of 10 animals each were formed. In order to protect cattle from zoophilic flies, the «Abifipr» composition was applied locally on the elevation between the horns or behind it in doses of $1.0 ; 2.5 ; 5 ; 7.5$ and $10.0 \mathrm{ml}$. Distilled water was applied to the animals in control group behind the elevation between the horns.

After processing, a daily count of the number of attacks of flies on experimental and control animals was carried out and the coefficient of protective action $(\mathrm{CPA})$ was calculated:

$$
\mathrm{CPA}=100-(\mathrm{A} \times \mathrm{B} 1 / \mathrm{B} \times \mathrm{A} 1) \times 100,
$$

where A1 and B1 - the number of insects on the experimental and control animals before treatment;

$\mathrm{A}$ and $\mathrm{B}$ - the number of insects in experimental and control animals after treatment.

Production tests were conducted in the pasture period from 2013 and 2014 in the farms located in the south of the Tyumen region of JSC «Bolshekrasnoyarskoye», the Omutinsky district, in LLC «Zubr» and SEC «Razhevsky» of the Golyshmanovsky district on adult cattle during various periods of zoophilic flies activity.

For extensive production tests, a group of cows or calves of at least 70 head was selected. For control purposes, a group of animals was left in the same conditions with the experimental one at a distance of at least $2-3 \mathrm{~km}$. Before processing, we conducted a count of the number of attacks of flies and determined their species composition. Counting for the number was performed by visual counting the number of insects on animals for a 3-minute record. More convenient and less laborious is the one-time counting of the number of insects on one side of the animal, carried out with the naked eye (according to K.A Breev) or using binoculars (according to Wilson), which, in connection with the possibility of multiple repetitions, provides more reliable data.

Production tests of «Abifipr» in a dose of $2.5 \mathrm{ml}$ per adult animal were conducted on the cattle belonging to the SEC "Razhevsky" of the Golyshmanovsky district in the period from May 10 to July 18, 2013. The experiment involved 74 head of young black-and-white breed. The control group in the number of 102 head was grazing at a distance of at least $5 \mathrm{~km}$ from the experimental animals and was not processed in any way.

«Abifipr» in a dose of $5.0 \mathrm{ml}$ per adult animal was applied to 86 animals located in «Bizon» LLC of the Omutinsky district in the period from July 20 to September 22, 2013. The group of 118 control head was grazing at a distance of $8 \mathrm{~km}$ from the experimental animals and was not processed in any way. «Abifipr» in a dose of $7.5 \mathrm{ml}$ per adult animal was applied to 72 animals located in «Zubr» LLC of the Golyshmanovsky district in the period from July 20 to September 13, 2013. The control drove of a cattle in the amount of 144 head was grazing at a distance of at least $5 \mathrm{~km}$ from the experimental animals and was not processed at all.

The drug was applied to animals in the morning before their releasing into pasture, except for unfavourable weather conditions days.

The safety of the treatment regimes was assessed by indicators of clinical status (behavior, food intake, body temperature, pulse rate and respiratory movements). 
The duration of the protective action of the insecticide was estimated by the number of zoophilic flies attacking the area around the eyes of animals of experimental and control groups, i.e. calculated the coefficient of protective action (CPA).

Accounting for the number of zoophilic flies around the eyes was carried out for 3 minutes before treatment and after 4 , $12,24,36,48,60,72,84,96,108$ and 120 hours after treatment.

\section{RESULTS}

It was established that for 24 hours after the application of «Abifipr», parasitism of zoophilic flies in the eye area of experimental animals was not recorded.

The first appearance of flies in the eye area was recorded after 36 hours in a group of animals, where $1.0 \mathrm{ml}$ of the preparation was applied. The number of flies was very low and for a three-minute count amounted $0.35 \pm 0.02$ individuals. Gradually, the number of parasites in the eye area increased and after 48 hours the abundance of flies was $0.80 \pm 0.30$ individuals, after 60 hours $-3.25 \pm 0.45$ individuals. In the following hours, the number of zoophilic increased and by the end of the observation (after 108 hours) the insecticidal effect was not recorded.

It is noticed that with an increase in the volume of the applied drug, the insecticidal effect was more pronounced. So, when applying $2.5 \mathrm{ml}$ of «Abifipr», a $100 \%$ protective effect was observed for 2 days, for the next 24 hours zoophilic flies showed interest in the eyes of animals, but their number was extremely low (0.20-1.74 individuals). Over time, the number of flies increased, but by the end of the observation, the protective effect was manifested for not less than $70 \%$.

Application of $5.0 \mathrm{ml}$ of the composition for 84 hours provided complete protection against zoophilic flies. By the end of the fourth day of observation, sporadic flies began to appear near the eyes of animals $(1.20 \pm 0.15)$, and by the end of the observation period, the protective effect was $86.35 \%$.

The application of the composition «Abifipr» in a volume of 7.5 and $10.0 \mathrm{ml}$ provided complete protection from zoophilic flies over the observation period.

The obtained data allow to summarize that the drug «Abifipr» applied by the pur-on method in doses of 5.0; 7.5 and $10.0 \mathrm{ml}$ provides $100 \%$ protection against zoophilic flies within 72 hours after application.

Considering the peculiarity of the effect of insecticides on a separate animal and when applied to a group, doses of $2.5,5.0$ and $7.5 \mathrm{ml}$ were selected for extensive production tests.

During the production tests of «Abifipr», it was established that the effectiveness of the drug depended on the dosage used and the activity of zoophilic flies (Figure 2).

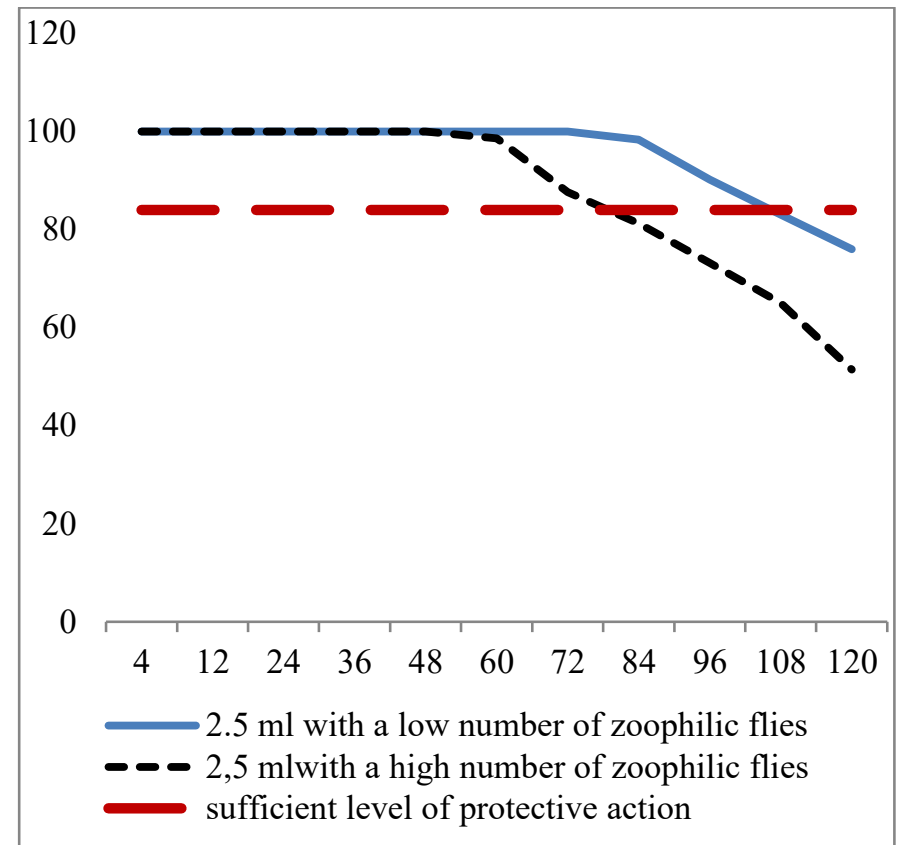

Fig. 2. Coefficient of protective action of «Abifipr» in a dose of $2.5 \mathrm{ml}$ against zoophilic flies

Thus, in the period of low abundance of zoophilic flies (during May and until mid-June, as well as in the second half of August until the end of the pasture season), the efficiency of «Abifipr» was higher than in the peaks of insect activity. When applying $2.5 \mathrm{ml}$, high protective effect (coefficient of protective action above $84 \%$ ) was observed for four days, then there was a smooth decrease of the protective action. The use of $5.0 \mathrm{ml}$ of «Abifipr» throughout the observation period ( 5 days) provided protection against zoophilic flies, as well as the use of $7.5 \mathrm{ml}$.

During the period of zoophilic flies activity (from the second or third decade of June to the second decade of August) the use of $2.5 \mathrm{ml}$ provided reliable protection for three days, after which the insecticidal properties of the drug were lost and did not protect against the attack of flies in the eye area.

Increasing the dosage of «Abifipr» to $5.0 \mathrm{ml}$ made it possible to protect animals from zoophilic flies for 5 days during the period of activity of zoophilic flies, as well as the use of $7.5 \mathrm{ml}$ of the preparation (Figure 3,4).

Observations of the insecticidal action of «Abifipr» in a period of low numbers of zoophilic flies showed that the subsequent recovery of the numbers of these insects occurs relatively slowly within a period of 7-10 days. 


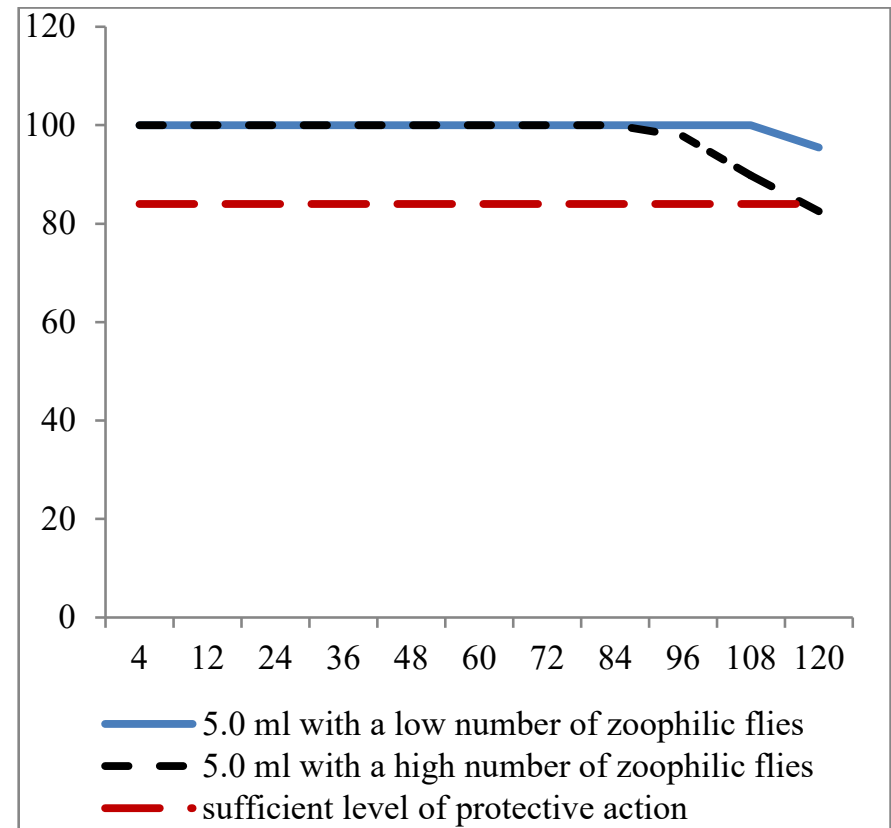

Fig. 3. Coefficient of protective action of Abifipr in a dose of $5.0 \mathrm{ml}$ against zoophilic flies

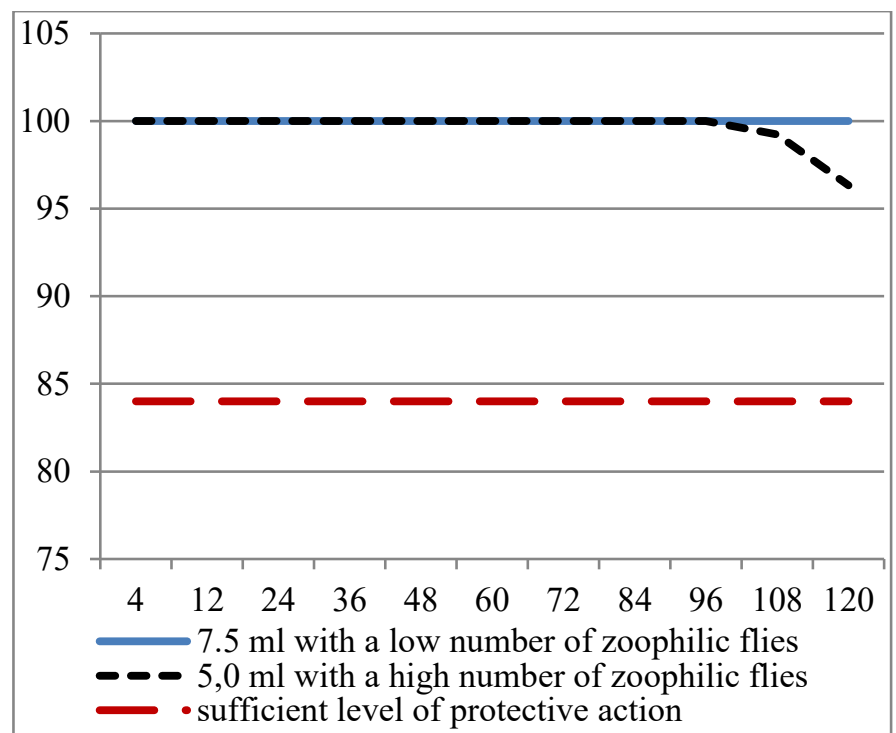

Fig. 4. Figure 4- Coefficient of protective action of Abifipr in a dose of $7.5 \mathrm{ml}$ against zoophilic flies.

Taking into account the results of preliminary tests, a dosage of $5.0 \mathrm{ml}$ was selected for extensive production experiments. Observations were carried out on cattle of the black-and-white breed of the repair young group in the number of 92 head in the APC (agricultural production cooperative) «Razhevsky» of the Omutinsky district in the period from May 12 to September 10, 2014. During this period, 17 treatments of animals were carried out, in the following mode: in the period of low population, the preparation was applied once in 7-10 days, in the period of high population once in 5 days.

The control group in the number of 81 head was grazing at a distance of at least $5 \mathrm{~km}$ and was not processed in any way.
Visual observations showed that the systematic use of "Abifipr» in a dose of $5 \mathrm{ml}$ in the indicated mode of use provided protection against zoophilic flies and the prevention of thelaziasis, since during the entire observation period they did not reveal a single case of thelaziasis.

The studied insecticidal efficiency and duration of the residual insecticidal action of the drug are essential components in the planning of anti-telazian measures. In practical terms, an important point is the economic rationality for the treatment of cattle against zoophilic flies in the conditions of the Northern Trans-Urals proposed by insecticides.

Since the use of «Abifipr» implies a local application of insecticide to or between elevations between horns, the labor costs for veterinary measures with this method are the highest and amount to around 3,000 rubles for the processing of a drove (one hundred head of cattle), compared to the automated methods of spraying water emulsions of insecticides, where cost of spraying the drug on the same number of animals is 800 rubles. Despite this, the price of insecticidal treatments of one cattle head for the entire season of activity of zoophilic flies by «Abifipr» turned out to be competitive and amounted to 794.92 rubles. This is due to the long period of residual insecticidal action of «Abifipr», which lasts 5.0 days with high activity of flies and 10.0 with their low numbers, which reduced the number of treatments that will require only $20.38 \pm 2.60$ for the whole season of parasitizm of zoophilic flies (depending on weather conditions).

\section{CONCLUSIONS}

The results obtained indicate a high efficiency of the drug «Abifipr» in a dose of $5 \mathrm{ml}$ (when applied to or between elevations between horns) against zoophilic flies (intermediate hosts of Thelazias) under production conditions. For the prevention of thelaziasis, it is advisable to apply «Abifipr» in a dose of $5.0 \mathrm{ml}$ to or behind the elevation between the horns once in 7-10 days in a period of low numbers of zoophilic flies and once in 5 days in a period of high activity of flies. The cost of insecticidal treatments per animal during the period of zoophilic flies activity was 794.92 rubles.

\section{Acknowledgement}

The article was prepared with the financial support of the FAO of Russia within the framework of the topics of FNI No. 0371-2018-0037 and the Basic Research Program of the Russian Academy of Sciences, registration number AAAAA18-118020690239-7 "Study of the effectiveness of new antiparasitic preparations".

\section{References}

[1] K.Arunachalam, V. Meenalochani, M.S. Kannadhasan, "Occurrence of Bovine Thelaziosis in Dharmapuri District”, Indian Vet. J., December. 2017, vol. 94 (12), p. 84.

[2] R.S. Bradbury, K.V. Breen, E.M. Bonura, J.W. Hoyt, H.S. Bishop, "Case Report: Conjunctival Infestation with Thelazia gulosa: A Novel Agent of Human Thelaziasis in the United States", Am J Trop Med Hyg, 2018 Feb 12, doi: 10.4269/ajtmh.17-0870.

[3] M.A. Chasovshchikova, O.M. Sheveleva, M.A. Svjazhenina, N.I Tatarkina, A.B. Satkeeva, A.A. Bakharev et al, "Relationship between the 
genetic variants of kappa-casein and prolactin and the productivebiological characteristics of cows of the black-motley breed", Journal of Pharmaceutical Sciences and Research, 2017, vol. 9, no 7, pp. 1038-1044

[4] O. Fiodorova, Y. Babin, N. Elatkin, A. Kononov, Trapping of culicoides midges in the European part of Russia in 2013, 2014,. pp. 96-97. [IV International conference Bluetongue and Related Orbiviruses, 2014]

[5] Yu. V. Glazunov, L. A. Glazunova, "Phenology of Pasture Ticks in The Trans-Urals", Indian Vet. J., January 2018, vol. 95 (01), pp. 19- 22.

[6] L.A. Glazunova, Yu.V. Glazunov, A.A. Ergachev, "Ecologicalepizootical situation on telasiosis among large cattle in northern ural region", Research Journal of Pharmaceutical, Biological and Chemical Sciences, July-August 2018, RJPBCS, vol. 9(4), pp. 1687-1693.

[7] S. V. Latkin, S. D. Pavlov, T. A. Khlyzova, O. A. Fyodorova, I. A. Metelitsa, M. V. Leshchev, "New preparations for protection of animals from dipterous blood-sucking insects", Rossiyskiy Parazitologicheskiy Journal, 2014, vol. 3(29), pp. 81-85.

[8] S.D. Pavlov, O.A. Fedorova, T.A. Khlyzova, E.I. Sivkova, "Study of efficiency: two preparation forms of repellant alezan", Journal of Pharmaceutical Sciences and Research, 2018, vol. 10, no. 7, pp. 1707 1710 .

[9] S. D. Pavlov, Metodicheskie rekomendatsii po izucheniyu effektivnosti repellentov i insekticidov v veterinarii. Moscow: VASKHNIL Publ., 1982.

[10] J.S. Ryu, K.I. Im, Y.J. Byun, S.C. Kim, "A case of human thelaziasis in Korea “, Kisaengchunghak Chapchi, 1987 Jun, vol. 25(1), pp.83-84.

[11] K. Samardžić, M.T. Paradžik, Ž. Janjetović, T. Živičnjak, Ž.V. Arar, F. Martinković, Ž. Siser, M. Miletić-Medved, "The first case of ocular thelaziasis in croatia", Acta Med Croatica, 2015, vol. 69(5), pp. 475-480.
[12] L. Skipin, E. Gaevaya, E. Zaharova, V. Petukhova, K Sidorova, "Biogeochemistry of heavy metals in trophic chain in terms of the south of Tumen region", Procedia Engineering, 2016, vol. 165, pp. 860-868.

[13] A.V. Sprygin, Y.Y. Babin, N.P. Elatkin, A.V. Kononov, O.A. Fiodorova, B. Mathieu, M.E. England, "Culicoides biting midges (diptera, ceratopogonidae) in various climatic zones of Russia and adjacent lands", Journal of Vector Ecology, 2014, vol. 39, no. 2, pp. 306-315.

[14] A.V. Sprygin, O.A. Fiodorova, Y.Y. Babin, A.V. Kononov, A.K. Karaulov, "Blood-sucking midges (Diptera: Ceratopogonidae) and their role in spreading blumtang and Schmallenberg diseases in Russia. Agrobiology", vol. 50(2), 2015, pp. 183-197. DOI: 10.15389/agrobiology.2015.2.183rus.

[15] O.A. Stolbova, "Acaricide activity of "Abifipr" medicine at dog demodicosis", IAJPS, 2018, vol. 05 (07), pp. 6594-6597

[16] O.A. Stolbova, Yu.V. Glazunov, L.N. Skosyrskikh, "Ticks-parasites of dogs in Northern Trans-Urals", Indo american journal of pharmaceutical sciences,, 2018, vol. 05 (03), pp. 1675-1682.

[17] S. Tasić-Otašević et al, "Eyeworm infections in dogs and in a human patient in Serbia: A One Health approach is needed", Comparative immunology, microbiology and infectious diseases, 2016, Vol. 45, pp. 20 22.

[18] Y. Yang, et al,. "Human thelaziasis occurrence in Taiwan", Clinical and Experimental Optometry, 2006, Vol. 89, no. 1, pp. 40-44.

[19] X. Zhao, et al, "Thelazia callipaeda infection in a 5-month-old infant", Infection, 2017, vol. 45, no. 6, pp. 907-910. 